\title{
Bir Anlamlandırma Yordamı Olarak Sanat
}

\section{Art as a Procedure of Signification}

\author{
Muhsin Yllmaz ${ }^{1}$
}

1Prof. Dr., Bursa Uludağ Üniversitesi, Fen-Edebiyat Fakültesi, Felsefe Bölümü, Bursa, Türkiye

ORCID: M.Y. 0000-0002-4687-6126

Sorumlu yazar/Corresponding author: Muhsin Yılmaz,

Bursa Uludağ Üniversitesi, Fen-Edebiyat Fakültesi, Felsefe Bölümü, Bursa, Türkiye.

E-mail/E-posta: myilmaz@uludag.edu.tr

Başvuru/Submitted: 02.04.2019

Revizyon Talebi/Revision Requested: 09.04.2019

Son Revizyon/Last Revision Received: 16.04.2019

Kabul/Accepted: 23.04 .2019

\section{Atıf/Citation:}

Yilmaz, Muhsin. "Bir Anlamlandırma Yordam Olarak Sanat." Felsefe Arkivi 50 (2019): 1-7. https://doi.org/10.26650/arcp2019-589806

\section{ÖZET}

Sahip olduğu potansiyeller ile bazen kendisini de nesneleştirerek kendisi ve kendisi dışındaki dış dünyayı anlama/anlamlandırma çabası içindeki insanın bu çabalarından birisi de sanat olarak ortaya çıkar. Ancak gerek biçimi gerek gönderimi ve gerekse gönderimine bağlı olarak anlamı açısından tanımlanmasının ve dolayısıyla neliği bakımından üzerinde uzlaşımının neredeyse olanaksız olduğu hayli tartışmalı bir kavramdır sanat kavramı. O kadar ki, farklı sanat türlerini ve biçemlerini kuşatıcı belki özcü denilecek bir sanat kavramını yadsımaya kadar varan bir belirsizlikten veya sınırsızıktan söz edilebilmektedir. Dolayısıyla bu yazıda tıpkı felsefe ve bilim gibi sanatın da anlamlandıran özne olarak insanın temel ve asli anlamlandırma yordamlarında birisi olduğu temellendirilmeye çalışılacaktır.

Anahtar Kelimeler: Sanat, anlamlandırma, aisthesis, tekhne, ars

\section{ABSTRACT}

The human being labours to understand and signify both the external world and himself - sometimes by objectifying himself with the potential he possesses; one of these labours emerges as art. Neither definition nor determination of the content of the concept of art is so clear cut because of its controversial nature in relation both to its different forms and references as the source of meaning. Some could assert even an ambiguity or boundlessness, insomuch as rejecting an essentialist concept of art encompassing all different kinds or forms of art. Therefore, this article attempts to ground the argument that art is one of the basic and constitutive procedures of signifying the external world - like philosophy and science - with the human being as the signifying subject.

Keywords: Art, signification, aisthesis, tekhne, ars 


\section{Giriş}

"İnsanı insan yapan en önemli etkinliklerden biri kuşkusuz 'anlam verme'dir" tartışmaya veya değerlendirmeye bir giriş olsun diye düşünülüp tasarlanarak yazılmış bu cümle, yeri ve zamanı geldiğinde -yani şimdi ve burada olduğu gibi- adeta bir bumerang gibi kendini irdeleyen/değerlendiren bir anlamlandırmanın konusuna/nesnesine dönüşebilir. Örneğin "insanı insan yapan etkinlikler" adı altında bir kategori yaratmak ve bu etkinlikleri önem sırasına göre sıralamak ve ayrıca anlam vermenin bizatihi kendisinin de bu sıralamanın başlarında geldiğini belirlemek veya söylemek anlam verip anlamlandırma çabasının tam da kendisi olsa gerekir. Eğer öyleyse, başlıktan sonra tırnak içinde aktarılan tümcenin içeriği burada bir kez daha doğrulanmış olmaktadır: İnsanı insan yapan en önemli etkinliklerden biri de çevremizde olup bitenlere bir biçimde "anlam verme" dir. Peki, eğer yine gerçekten söylendiği gibiyse durum, o zaman insanın "anlam verme" etkinliği nasıl bir işlemdir, edimdir veya süreçtir? Ya da aynı metinde değinildiği gibi anlamlandırma kavramının içlemi nedir?

Anlamlandırma işlemi veya edimi için en azından, anlamlandıran ve anlamlandırılan olarak iki tarafın veya ögenin olması gerekir. Hatta iki öge arasındaki anlamlandırma işleminin kendisi de belki bir üçüncü öge olarak kabul edilebilir. Dolayısıyla insanın en önemli etkinliklerinden biri olan anlam verme veya anlamlandırma yordamlarından birisi olarak sanatsal anlamlandırmaya geçmeden önce, değil mi ki şimdi yaptığımız da, yani belirli türden işlemleri "sanatsal” olarak niteleyip belirlememiz de bir sınıflandırmadır, o halde öncelikle anlamlandırma işleminin/ işlevinin türlerinden söz etmenin mümkün olduğunu kabul etmemiz gerekir. Bu durumda en azından anlamlandıran ile anlamlandırılan arasında birden çok anlamlandırma biçemi/yordamı olduğu söylenebilir demektir. Bu da şu anlama gelir ki, anlamlandıranın anlamlandırılanı anlamlandırabilmesi için birden çok yetisi/kapasitesi söz konusudur ve bundan dolayı da farklı yordamlardan söz edilebilmektedir. Ya da birden çok yordamdan söz edebiliyorsak bunların en azından sonuçlarında, prosedürlerinde ve hatta belki de kaynak veya kökenlerinde de farklılıklar olmalıdır. Örneğin anlamlandıran özne olarak insanın sezgisel, akılsal, deney(im)sel ve hatta iradi yetileri olduğu söylenir. ${ }^{2}$ Bizim sınıflandırmamızla, yalnızca ve yalnızca anlamlandırabilmek için bu yetilere karşılık gelen anlamlandırma biçemi ya da yordamlarına sırasıyla sanat, felsefe ve bilim adlarını verirsek, anlamlandıran özne olarak insan anlamlandırma işlemini/eylemini, belli başlı üç biçimde/çerçevede gerçekleştirmekte veya başarmaktadır. Yine sözgelimi bunların her birinin başat olarak etkin olduğu anlamlandırma biçemi/yordamı ve dolayısıyla işleminin sonucu ya da sonuçları da, diğerlerinin başat olduğu biçemlerden/yordamlardan farklı olacaktır -tıpkı farkı duyu organlarının aynı nesneyi kendilerince duyumlayıp göstermeleri veya anlatmaları örneğinde olduğu gibi. Örneğin sanat tarihi, felsefe tarihi ve bilim tarihi ya da bunların her birini oluşturan sanat akımları, felsefi sistemler ve bilim kuramları gibi. Dolaysıyla sanatsal, felsefi ya da

1 Ekren, U., Felsefenin Perspektifinden J. S. Bach'in ve Richard Wagner'in Sanatı, s.19

2 Örneğin Diderot Bacon'a atfen benzeri bir sınıflandırmayla ve üstelik her birini bir anlamlandırma çerçevesiyle ilişkilendirerek insanın yetilerini hafıza (tarih), akıl (bilim/felsefe) ve hayal gücü (şiir/sanat) olarak sınıflandırır (Diderot, D’Alembert, 1996, s. 95-103). Dahası benzeri sınıflandırma Ortaçağın trivium ve quadrivium ayrımı biçiminde ifade edilen liberal sanatlar sınıflaması üzerinden Aristoteles'in bilinen/klasik bilimler sınıflamasına kadar geri götürülebilir. 
bilimsel anlamlandırma yordamlarından herhangi birinin diğerinin işlevini yerine getiremeyeceği ve bu nedenle de herhangi birisinin bir diğerine göre değer bakımından değerlenemeyeceği anlamlandırma yordamlarından yalnızca sanatın veya sanatsal anlamlandırma yordamının neliğini belirleyip tanımlamaya çalışmak buradaki temel amacımızı oluşturacaktır.

\section{Ne İçin Sanat?}

Anlamlandırma yordamlarından her birinin neliğini ayrı ayrı belirleyip tanımlama yerine kendimizi daha çok sanatın neliğini belirlemekle sınırlamak istediğimiz bu soruşturmada bir bakıma, tartışmalı mı tartışmalı "Sanat nedir?” sorusunun peşinden koşacağız, yakalayabilirsek onu yakalamaya ya da yaklaşabildiğimiz kadar kendisine yaklaşmaya çalışacağız.

Örneğin bir görüşe göre, ““Sanat” adı verilen bir şey yoktur aslında, yalnızca sanatçılar vardır; yani bir zamanlar renkli toprakla bir mağaranın duvarına becerebildiklerince bizon resimleri çiziktiren, bugünse boya satın alıp reklam afişleri yapan ve yüzyıllardan beri daha birçok başka şeyler üreten insanlar. Tüm bu etkinlikleri sanat diye tanımlamakta hiçbir sakınca yok, yeter ki bu sözcüğün yer ve zamana göre birbirinden değişik anlamlara gelebileceği unutulmasın ve günümüzde neredeyse bir korkuluk veya tapınç aracı haline gelen ve büyük $S$ ile başlayan Sanat'ın var olmadığının bilincinde olunsun"3. Peki, bu durumda adına sanatçı denen kişilerin yani zanaatkarların hem yaptıkları işe hem de bu iş sonunda ortaya çıkardıkları ürüne/nesneye (yapıta?) ne diyeceğiz? Sanat ürünü veya sanat yapıtı demeyecek miyiz? Diyemez miyiz? Ya da "Sanat" sözcügünün/teriminin karşılık geldiği bir kavram yok mudur? Bir kavramın da en azından bir içlemi ve dolayısıyla bir tanımı yok mudur? Örneğin; "bir duygu, tasarı, güzellik vb.nin anlatımında kullanılan yöntemlerin tamamı veya bu anlatım sonucunda ortaya çıkan üstün yaratıcılık" gibi sanat için yapılan bir tanım anlamsız mıdır? Ya da "duyguları, kabul edilmiş ve beklenen kökenlerinden ayırmak bizatihi sanatın görevidir... Sanatta sunulduğu şekliyle duygu, sözcükler ve deneyimler arasında kurduğumuz gündelik ve kanıya dönüşmüş bağlantıları yıkar... Kabul edebileceğimiz tek şey sanatın bilgiye dair olmadığıdır; "anlamlar" aktarma veya enformasyon sağlama gibi bir amacı yoktur sanatın... Sanatı sanat yapan, içeriği değil, duygusudur, içeriği üretmesini sağlayan duyusal güç veya üsluptur" ${ }^{5}$ biçimindeki tanım, tespit veya değerlendirmeler neye ilişkindir? Özcü denilebilecek bir sanat anlayışını ifade etmek üzere büyük "S" ya da anti özcü sanat anlayışı için küçük "s" ile ama nasıl yazılırsa yazılsın deneyimlerimiz de göstermektedir ki insanların yaşamında adına "sanat" dedikleri bir olgu vardır. Yine deneyimlerimiz aynı açıklıkla, sanatın örneğin siyasetten veya tarımdan değişik bir şey olduğunu da göstermektedir ${ }^{6}$. Ayrıca yukarıda değinildiği gibi en azından kavram olarak sanat kavramının içlemi siyaset ve tarım kavramlarının içleminden farklıdır ki sanıyorum o farklılık da, her ne kadar kesinlikli biçimde sınırlanıp tanımlanamasa bile sanat kavramının altında toplanabilen faaliyetler veya faaliyet sonuçları olacaktır. Bu açıdan değerlendirilecek olursa sanat kavramının belirsizliği, tanımlanabilirliği ve giderek üzerinde uzlaşılabilirliği bir yana, felsefe

3 Gombrich, E. H., Sanatı Öyküsü, s. 4

4 Türkçe Sözlük. T.D.K. İstanbul, 1992

5 Colebrook, C., Gilles Deleuze, ss. 38-39

6 Gombrich, a.g.y., s. 5 
ve hatta bilim kavramı da açık bir biçimde tanımlanabilirliği açısından tartışmalı bir kavram değil midir? Dolayısıyla tanımlanabilirliği açısından felsefe ve bilime göre belki de yordamı bakımından daha güç bir kavram olsa da, en azından büyük "S" ile başlayan bir sanat kavramının anlamsızlığından söz edilemez.

Ancak öte yandan göreli olarak daha modern zamanlara özgü olan bu tartışmanın öncesinde klasik dönemde, bugün bizim zanaat ve sanat olarak ayırdığımız kavramların karşılıkları olan tekhne $e^{7}$ ve $a_{r s}{ }^{8}$ terimleri de bir o kadar çok anlamlı ve dolayısıyla tanımlanması güç kavramlardı. Örneğin bir değerlendirmeye göre hem tekhne hem de ars, bir nesneler sınıfından daha çok insanlardaki imal ve icra etme yeteneğini ifade eden terimlerdi. ${ }^{9}$ Bundan dolayı tekhne eski dünyada tıp ve askeri stratejiden tutun da çömlekçilik ve şiire kadar uzanan çeşitli sanatların icrası için kullanılan bir terimdi. Burada ilginç olan nokta, bugün zanaat eseri denilen nesnelerle sanat yapıtı olarak nitelenen nesnelerin aynı kategoride sayılıyor olmasıdır. Örneğin çömlekçilik zanaatı ile şiir sanatının ortak paydası, her ikisinin de bir şeyi ustalıklı ve incelikli biçimde yapabilme becerisinin veya yeteneğinin sonucu olmalarıdır. Dolayısıla tekhnites, yani zanaatkar veya sanatçı olan insanlar, yine Shiner'ın tanımlamasıyla hepsi hepsi becerikli ve incelikli icracılardır. Bir başka örnek vermek gerekirse, "Aristoteles için, her ikisi de taklit sanatı olan resimle trajedinin ortak yönleri, yordam (procedures) itibarıyla ayakkabıcılık ya da hekimlik gibi sanatlardan ayrı kılmıyordu kendini." ${ }^{10}$ Bundan dolayı sanki sanatçılar da tıpkı ayakkabıcılar gibi, kendilerine sipariş edilen herhangi bir ürünü/malı tedarik eden kimselerdi. Ancak burada bir başka önemli nokta, zanaatçı ya da sanatçı olarak becerikli insanların aynı zamanda incelikli insanlar olmalarıdır. Yani yaptıkları işin ya da ürettikleri nesnenin sıradan olmak yerine zarif, güzel, şık olmasıdır. Benzer bir değerlendirme ars terimi için de yapılabilir. Her ne kadar köken olarak yöntem, usül, vasıta gibi anlamları olsa bile, bunların yanında ustalık, yetenek, hüner gibi anlamlarıyla tekhnenin taşıdığı incelik ve zarafet anlamlarını da içermektedir. Dolaysıyla klasik dönemin tekhne ya da ars terimlerinin anlamları da, modern dönemlerin sanatının içerimlerinden olan, bir duygu, tasarım ya da güzelliğin anlatımında kullanılan yöntemlerin tamamı veya bu anlatım sonucunda ortaya çıkan üstün yaratıcılık; bir şey yapmada gösterilen ustalık ve incelik tanımının dişında değildir.

\section{Sanat: Estetik Deneyim}

Öte yandan insanın deneyim dünyasında adına "sanat" denilen bir deneyim türü ya da kategorinin olup olmadığı sorunu yanında bir de varlığı kabul edildiğinde, söz konusu deneyimin nasıl bir deneyim olduğu ve dolayısıyla sanat kavramının içeriği ya da içleminin ne olduğu da ayrı

7 Tekhne: yapabilme gücü, kabiliyet, yetenek, zanaat; bir şeyi yapmanın düzenli yöntemi; kurnazlık, marifet, hilebirşeyi yapabilmenin ya da elde edebilmenin yolu, yordamı, tarzı, adeti, aleti olan araç; sanat beceri, zanaat, meslek, bir sanat ürünü veya eseri, (Francis E. Peters, Antik Yunan Felsefesi Teirmleri Sözlüğü, Paradigma Yayınları, İstanbul, 2004

8 Ars: Yöntem, usul, vasıta; sanat, zanaat; ustalık, yetenek, hüner (herhangi bir sanatta); sanat eseri, ahlaksal nitelik erdem, oyun, hile, desise, kurnazlık, (Sina Kabaağaç ve Erdal Alova, Latince-Türkçe Sözlük, Sosyal Yayınlar, İstanbul, 1995

9 Shiner, Sanatın İcadı, s. 49

10 Shiner, a.g.y., s. 51 
bir sorunsal gibi görünmekte. Çeşitli duygulanımların farklı malzeme veya araçlarla ifade edil(ebil) mesinden dolayı farklı sanat türlerinden/biçimlerinden söz edebilmek için öncelikle farklı sanat türleri ve biçimlerini kendi içleminde toplayan ortak bir kavramın olması gerekir. Ayrıca bir de insanın, ancak sanat kadar tanımlanabilir ya da tanımlanamaz olan güzellik kavramının içeriği/içlemi olarak güzellik olgusunu algılayışı ile ilişkilendirilen estetik kavramından söz edilir. Kavramın kökeni olarak aisthesis teriminin en azından anlamlarından birisi olan duyumsal deneyimin öznelliği ile ilişkilendirildiğinden olsa gerek, ne güzel kavramı ne de onu yakalayıp yansıttığı veya taşıdığı da düşünülen sanat kavramı ele avuca gelmez biçimde aramızda uçuşup duruyor adeta. Yani bir taraftan yakalanıp da tespit edilemediğinden tanımlanamaz olan ama diğer yandan da vazgeçilemezcesine peşinden koşulan bir olgu ya da kavram durumunda sanki güzellik. Demek peşinden koşan için peşinden koşulması gereken veya peşinden koşmaya değer bir değer 'güzellik'. Niçin kendisinin peşinden koşulduğun sorulacak olursa eğer, o zaman da hani olur ya, bir kez olsun yakalandığında ya da yakalandığı sanıldığında yakalayanda ne olup bittiğine bakmak gerek. Örneğin Aristoteles'e göre, (doğanın kendisinden başka) güzelin veya güzelliğinin taşıyıcılarından olan sanattan alınan zevk (veya duygu), kopyanın kusursuzluğunun insanda uyandırdığı hayranlık ve bu kopyanın zararsız bir canlandırma nesnesine indirgenmiş olması

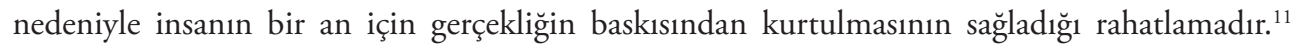
Tabii burada güzelliğin veya güzel olanın/bulunanın ne olduğu da sorulabilir: Temsili veya taklidi yapılan nesne ya da olgu mudur yoksa temsil ya da taklidin tarzı veya sunuluş biçimi midir "güzel” nitelemesine konu olan? Aristoteles'e göre taklidin yetkiliğidir seyredeni ya da izleyeni hayran bırakan. Zira "gerçeklikte hoşlanmayarak baktığımız bir nesne özellikle tamamlanmış bir resim haline geldiğinde, bu kez ona hoşlanarak bakarız; örneğin tiksinti uyandıran hayvanların ve cesetlerin resimlerinde olduğu gibi" ${ }^{\prime 2}$. Keza polisiye romanlar veya korku filmleri gibi daha modern örnekler de aktarılan öykü içeriklerinden çok öyküleme biçimleri ya da üsluplarının yetkinliği yüzünden okunuyor ya da izleniyor olsa gerekir. Peki, o zaman bir öyküyü, yani bir nesne veya bir olguyu öyküleme biçimini/tarzını izleyip peşinden gitmeye değer kılan özellik(ler) ne(ler)dir? Nasıl olursa izleyici için hoşlanılası olur bir öykü veya öyküleme? Ya da izleyici açısından sorulduğunda, bir izleyici bir sanatsal anlatımı niçin ya da hangi niteliğinden dolayı izlenilesi bulur? Örneğin gördüğü anlatım biçiminde kendinden bir iz gördüğü için olabilir mi? Ya da daha öncesinde hiçbir biçimde görmediği bir unsur mu onu kendisi için bakılmaya/ izlenmeye değer kılar? Yine örneğin bir görüşe göre insan, gördüğünü bakmaktan veya işittiğini dinlemekten, yani onu temaşa etmekten hoşlanmayı zamanla öğrenirmiş. Hatta bir anlatıya göre, İgor Stravinski Bahar Ayini nin ilk seslendirilişinde karşılaştığı yoğun protestolar nedeniyle kaçarcasına terk ettiği salonlardan bir iki yıl sonra yine aynı eserin seslendirilişinin ardından omuzlarda alkışlarla ayrılmaya başlamıştır. O kadar ki Lehrer'in anlatımıyla eser ilk seslendirilişi sırasında yaşlı kadınlar genç estetlere saldırıp baletlere hakaretler yağdıırken, galadan birkaç yıl sonra, muhtemelen aynı sanat çevrelerince Ayin ayakta alkışlanıp, Stravinski salondan kalabalığın omuzlarında çıkarılır olmuş. Çünkü artık dinleyiciler senfoninin titremelerinde saklı olan korkutucu 'güzelliği' en nihayetinde keşfetmişler ve senfoninin hoş kalıplarını duyabilir olmuşlar

11 Beatrice Lenoir, Sanat Yapiti, s. 47

12 Aristoteles, Poetika, 1448 b vd. 
(!). Çünkü eğer yine sinirbilimcilere sorarsanız, kimilerinin kimi zaman nice nice değerler veya anlamlar yüklediği müzik aslında nihayetinde insan yapımı olan ve işitmesini öğrendiğimiz bir gürültüler derlemesinden başka bir şey değilmiş. ${ }^{13}$

Ancak öte yandan hem Stravinski örneğine karşın hem de her ne kadar Aristoteles aksini ileri sürse de ${ }^{14}$ izlemeyi veya dinlemeyi öğrenecek kadar zaman geçip de deneyim edinmeden daha ilk karşılaşmamızda “çok mu çok!” hoşlandığımız hatta hayran kaldığımız (!) estetik deneyimler yok mudur/olmaz mı? Yoksa bir başka olasılık olarak her iki deneyim de, yani ilk karşılaşma deneyimleri ile tekrarlama şansının olduğu deneyimler farklı türden ya da farklı nitelikte estetik deneyimler midir? Sözgelimi bir yanda dönemi için avangart olarak nitelenen sanatın tipik örneği sayılabilecek Bahar Ayini nin yarattığı tepkilerin zamanla yatışması(!), yani olağanlaşması; diğer yanda ise kişisel beğeniye bağlı olarak yaşanılan estetik deneyime konu olan nesne veya olgu ile daha ilk karşılaşmada estetik öznede ortaya çıkan beğeni duygusu veya tepkisi -örneğin deniz üzerinden batan bir güneş olgusu veya fotoğrafı örneğinde olduğu gibi. Aynı, benzer ya da farklı nasıl olursa olsun, ama bir estetik deneyim sırasında izleyende ne olup bitmektedir? Ki deneyimin sonunda/sonucuna göre beğenme/beğenmeme gibi farklı ve hatta karşıt tepkiler ortaya çıkabilmektedir? Örneğin yine Aristoteles'e göre, kusursuz bir ölü hayvan imgesinin bize verdiği zevk ancak, sanatçının üstün becerisiyle ve ürettiği işin gerçekdışı özellikte olması, bunun da huzursuz olan izleyiciyi bir şey yapma zorunluluğundan kurtarmasıyla açıklanabilir. Yani bir sanat yapıtı ile yaşanan estetik deneyimden bir zevk duygusu alınmakta ve bu zevk duygusu da muhtemelen, deneyimlenen ölü hayvan imgesinden herhangi bir tehdit/tehlike gelmeyeceğini kavrayıp öğrenmiş olmaktan kaynaklanmaktadır. Nitekim Aristoteles yukarıda aktardığımız, gerçeklikte tiksinti uyandıran hayvan cesetlerinin resimlerinden hoşlanma veya beğenme durumunu bu kez "öğrenmenin verdiği derin hoşlanma” ile gerekçelendirir. Demek estetik deneyim derken biz yalnızca estetik özne ile estetik nesne arasında gerçekleşen saf bir estetik deneyimden değil, aynı zamanda bir öğrenmeden de söz ediyoruz, bir öğrenme deneyimi yaşıyoruz. Peki, öğrenmek neden ve nasıl bir hoşlanmaya yol açar? Aristoteles’in, duyulardan alınan zevki kanıt olarak gösterdiği doğal bilme güdüsü müdür hoşnutluğun kaynağı yoksa örneğin, bilmenin nesnesine ilişkin belirsizliğin giderilmesinden duyulan rahatlamanın yarattığı bir hoşnutluk mudur? Ancak öğrenmeyi işin içine katarsak bu kez estetik deneyim için bir çıkar güdüsü devreye girer ki bu durumda da Kant için bir estetik deneyim olmaktan çıkar yaşanılan. ${ }^{15}$ Sonuç olarak amaçlı ya da amaçsız, öznel ya da evrensel ama her durumda yaşanılan deneyimi bir biçimde anlayıp adlandırmak gerekir. Böylece de estetik deneyimin nesnesi veya konusu hakkında, örneğin beğenme karşılığı olarak "güzel” ya da beğenmeme karşıllı̆ı olarak "güzel değil” biçimindeki bir estetik yargı ile yaşanılan estetik deneyimi anlamlandırmak yani tamamlamak gerekir.

Finansal Destek: Yazar bu çalışma için finansal destek almamıştır.

13 Lehrer, J., Proust Bir Sinirbilimciydi, ss. 135-154

14 Aristoteles, a.g.y, $1148 \mathrm{~b}$ vd.

15 Zira "Kant’a göre bir yargıyı estetik yapan özellik, onun haz ya da hazsızlık duygusu sonucunda doğup doğmamasıdır. Bu durum, doğan bu yargının bilgi dışı olduğunun da göstergesidir. Çünkü duyguların hiçbir bilgi işlevi yoktur. Estetik yargı, yönelinen nesneden çok, ona yönelen öznenin duygu durumuyla ilgilidir” (Keskin, s. 30). 


\section{Kaynaklar}

Aristoteles, Poetika, çev. İsmail Tunalı, Remzi Kitabevi, İstanbul, 1983

Colebrook, Claire, Gilles Deleuze, çev. Cem Soydemir, Doğu Batı Yayınları, Ankara, 2013

Ekren, Uğur, Felsefenin Perspektifinden J.S. Bach ve Richard Wagner’in Sanatı, Sentez Yayınları, İstanbul, 2016

Gombrich, E.H., Sanatın Öyküsü, çev. Bedrettin Cömert, Remzi Kitabevi, İstanbul, 1980

Kabaağaç, Sina; Erdal Alova, Latince-Türkçe Sözlük, Sosyal Yayınları, İstanbul, 1995

Keskin, Gamze, Kant Estetiği ve Romantisizm, Alfa Basım, Yayım, Dağıtım, İstanbul, 2019

Lehrer, Jonah, Proust Bir Sinirbilimciydi, çev. Ferit Burak Aydar, Boğaziçi Üniversitesi Yayınları, İstanbul, 2009

Lenoır, Beatrice, Sanat Yapıtı, çev. Aykut Derman, YKY, İstanbul, 2003

Peters, Francis E., Antik Yunan Felsefesi Terimleri Sözlüğ̈̈, Paradigma Yayınları, İstanbul, 2004

Shiner, Larry, Sanatın İcadı, çev. İsmail Türkmen, Ayrıntı yayınları, İstanbul, 2004

Türkçe Sözlük, Türk Dil Kurumu, İstanbul, 1992 
